\title{
Development of information-analytical system for technological requests monitoring, taking into account regional specifics
}

\author{
Grechukhin Aleksandr Nikolaevich \\ Candidate of Engineering Sciences, Associate professor of \\ the sub-department «Engineering technologies and \\ equipment» \\ Southwest State University \\ Kursk, Russia \\ E-mail: Agrechuhin@mail.ru) \\ Razumov Mikhail Sergeevich \\ Candidate of Engineering Sciences, Associate \\ professor of the sub-department «Engineering \\ technologies and equipment» \\ Southwest State University \\ Kursk, Russia
}

\author{
Kudelina Daria Vasilevna \\ Candidate of Engineering Sciences, Teacher of the Power \\ Supply Department \\ Southwest State University \\ Kursk, Russia
}

Anikutin Ivan Sergeevich

Student of the sub-department «Engineering technologies and equipment»

Southwest State University

Kursk, Russia

\author{
Byshkin Alexander Sergeevich \\ Postgraduate of the sub-department «Engineering technologies and equipment» \\ Southwest State University \\ Kursk, Russia
}

\begin{abstract}
The article analyzes the problems of mass application of additive technologies in the industrial sector of the region. It is shown that it is the high cost of the material that is one of the problems of additive technologies transferring to the technological processes of machinebuilding enterprises of the Kursk region. It is proposed to create a regional center of additive technologies, which will be the industrial and innovative center of the region. Another problem of the additive technologies transfer is the awareness lack of the regional industrial sector connected with the possibilities of providing services in the field of additive production technologies and the needs of enterprises for such services. In order to solve these problems, the authors have developed the system for technological requests monitoring for products and additive production technologies, the tasks of which are the operative monitoring of technological requests and proposals. Also the model and the methodology for its application were developed
\end{abstract}

Keywords-Monitoring system, technological request, technological offer, automation, additive technologies

\section{INTRODUCTION}

Formation of the surface of engineering parts is the central task, solved in the process of production of engineering parts. Currently, there is a steady trend towards producing products that satisfy the need for new ways of shaping products. According to the classification of shaping methods proposed by M. Burns [1], there are the following methods of forming: subtractive, additive and formative.

The additive method is a method of forming, based on the layerwise addition of material volumes.

As a result of the analysis of published sources [2-5], it is revealed that there is no generalized model describing the relationship of materials and technologies. This is due to continuous modernization, technical progress and the creation of new ways of layer-by-layer cultivation of products [3].

Based on the analysis, a block diagram was constructed describing the interrelationships between materials and technologies for additive production, in which, depending on the aggregate state, the type of material, its production state, by imposing constraints, it is possible to determine the technology and additive production method that is possible to apply for layer-by-layer cultivation of products from various materials (Figure 1).

According to the analysis of the literary sources, there are the following advantages of the use of additive technology in the processes of machines and mechanisms parts manufacturing [6-12]: 
- Reduction of the production cycle time for the piece

- Reduction and simplification of the logistics chains. and the small-batch production.

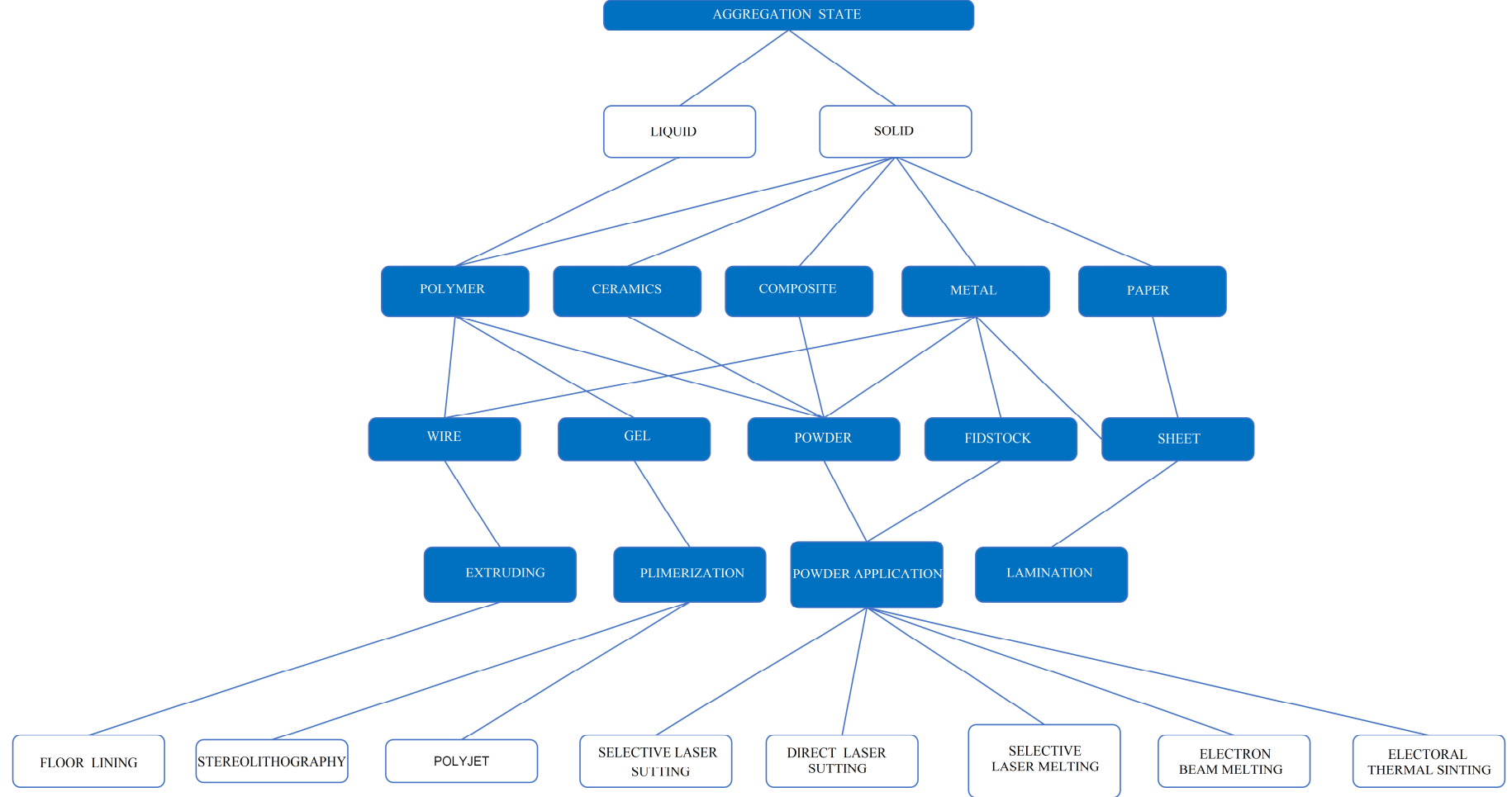

Fig. 1. Classification of additive production materials and technologies

- The use of fundamentally new approaches to the design of the products that makes it possible to create complex parts that cannot be manufactured by the traditional machining methods.

- Saving of materials - in the processes of additive technologies is used the amount of material that is necessary for the production of a product.

- Simplification of production processes for the manufacture of the details.

However, despite the obvious advantages of additive technologies applying in industrial processes, in the regions the technology of layer-by-layer product cultivation has not been widely used - in the Kursk region at the most industrial enterprises the use of traditional machining technologies prevails in technological processes.

\section{ReleVAnCE AND PROBlem StATEMENT}

One of the problems of the additive technologies transfer and integration in the technological processes of high-quality domestic products manufacturing are $[13,15]$ :

- The high cost of the material and technical base of additive technologies. Technique for realizing the possibilities of additive production technologies is imported product for which correct and continuous work the imported materials, software are required.
- The lack of the regulatory framework - the standards used in the industry at the moment, do not contain information about additive technologies.

- Low level of awareness of the industrial enterprises supervisors about the capabilities of the region's leading innovation centers in the field of additive technologies.

- Low level of awareness of leading industrial centers about the regional industrial enterprises needs in additive technologies.

Thus, there are a number of the updated problems which have a negative impact on the efficiency of the additive technologies transfer to the industrial sector of the region.

\section{THEORY AND PRACTICAL IMPLEMENTATION}

In the absence of material and technical basis for the implementation of additive technologies, the task is to identify and systematically monitor the technological demands of the industrial sector enterprises, as well as the development of draft technology proposals from regional engineering centers and industrial centers which can have the significant impact on the long-term socioeconomic development. Systematic tracking of technological requests for additive technologies and the formation of technological proposals will help to inform the regional scientific and industrial sectors and, accordingly, to improve the efficiency of the additive technologies transfer to the real sector of the economy. 
The effective centers for technological requests monitoring are regional centers of additive technologies, which unite the majority of the regional engineering activities, corresponding to the profile of the center. The team of the centers consists of the competent specialists who have completed additional training and internships in the relevant foreign companies and universities that have appropriate educational programs and laboratories $[14,16]$.

The center for additive technologies promotes:

- processes of modernization and technological reequipment of industrial enterprises;

- transfer of innovative technological developments into production;

- creation of prerequisites and organization of the process of import substitution of technologies, equipment, materials.

An effective tool for realizing the tasks of technological requests monitoring is the creation of the information and analytical systems for such monitoring.

The existing information and analytical systems for technological requests monitoring often do not provide the sufficient information, limited by publication of texts of requests on Internet resources. In regions, due to the specific features of innovative development, the link between the scientific and industrial sectors is lost, which leads to the negative consequences associated with the slowdown in the economic development.

The availability of complete and reliable information on the technological request is the basis for the preparation of a technology proposal aimed at finding partnersin the field of scientific and technological cooperation aimed at increasing the competitiveness of domestic products.

To carry out an operative collection of information on the technological requests of the regional industrial sector for products and technologies of the additive production, the authors have developed information and analytical monitoring system [17].

The algorithm of the information-analytical system is shown in the Fig. 2 and is based on the classification of materials and technologies of additive production, proposed above. The application of the technological requests monitoring system for additive technologies solves the problem of minimizing the costs of resources to find the necessary technological solution in accordance with the technological request on the use of the additive technologies.

The peculiarity of the proposed system is that its users can be people who are not specialists and experts in the subject area of additive technologies.

Developing the system, the authors followed the path of maximum simplification of the interaction processes between the user and the resource.
One of the main elements is the form of the technological request, which is formed by an expert method and contains information about:

- Brief description of the currently used technological process;

- Information about the problems which have arisen;

- Benefits for the consumer;

- Information about the company / organization that issues the technological request.

This form should contain only key information, because the detailed technical description makes it difficult to find a solution.

The above code fragment is a form implementation using the HTML markup language and cascading style tables. This form is subject to placement on the Internet portal which allows you to effectively capture key information. However, the request form carries only information you need to know to understand the essence of the technological request.

In order to create a full-fledged system for additive technologies technological requests monitoring, the obtained data were tied to the certain automated work algorithm.

Therefore, an important task was to create a set of guiding questions that will help to translate the process of manual work into an automatic one. For this, following the collection of results, a database was created, by collecting answers to sorting questions. The principle of this distribution is: it is first necessary to choose the aggregate state of the substance used in the technological process of detail manufacturing (solid or liquid); depending on the previous answer, the system suggests making a choice from the next list. If the liquid state is selected, the system automatically determines that it is a polymer, and offers a list of production conditions (wire, gel, powder). If the state is solid, the system asks which material is used: ceramics, composite, metal, paper, and further, depending on the selected material, certain actions are performed. If a metal is selected, it is also necessary to choose the material used: wire, powder, feedstock or sheet. For composites, ceramics and paper, the system itself determines the material (composite, ceramic - powder, paper - sheet).

The final step is to determine the production method: if powder or feedstock is selected, powder coating is automatically selected, and further application types are provided (selective laser sintering, direct laser sintering, selective laser melting, electron beam melting, selective thermal sintering). For a sheet, lamination is determined; for gel - polymerization, where you can choose stereolithography or POLYJET; for wire - extrusion (layered surfacing).

After the distribution, all requests are entered in the corresponding table of the relational database. Most databases have a table structure, which consists of many related tables. In the table, the data address is determined by the intersection of rows and columns. For each type of processing, a table is 
created in the database, in which all information about the relevant request is stored. The database is an SQL database, data management is performed using SQL queries.

Thus, each technological request, depending on the selected parameters, replenishes the corresponding database table.

The next action of the information-analytical system is the search for a database with the proposals of enterprises, if the query data coincide, then the result is about the presence of the proposal for a particular query. A selection is made of all organizations where the corresponding type of opportunities in the field of additive technologies occurs and sorts the results of the query by name. After selecting an organization, the system sends a request for the possibility of accomplishing the task, if there are no organizations, then the proposal is sent to all who entered the list on the request made. After confirmation of execution, the request is marked as completed and is sent to the archive [18].

Thus, by establishing certain selection criteria, it is possible to automate the system of requests distribution and proposals, which makes it possible to create a system that, based on the data already available, will independently compare the available request and the corresponding organization that has the necessary resources in the field of additive technologies.

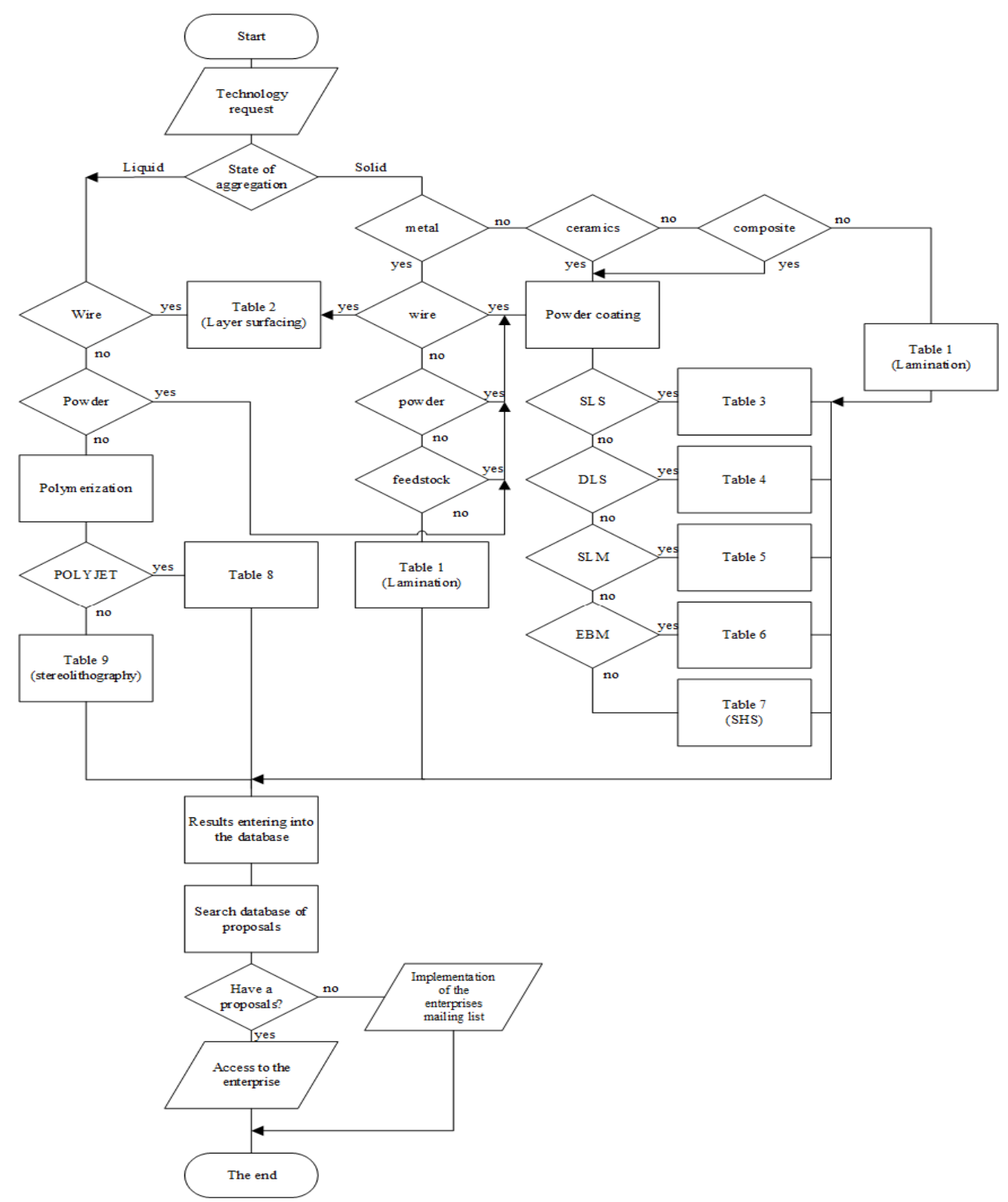

Fig. 2. Algorithm of the information-analytical system work of technological requests monitoring for the additive production products and technologies 
The result is an intelligent decision support system that not only collects data, but also brings them to the end user, that is an important element in finding solutions to the problems in the field of additive technologies.

The limited volume of the article makes it difficult to describe in detail all the operations of creating and applying the system of technological requests automated monitoring, therefore only the main works of this system were considered.

\section{DISCUSSION OF RESULTS}

The above-mentioned information and analytical system for technological requests monitoring of the additive production products and technologies allows to receive automatically information on technological proposals and to direct the response to such requests in the form of technology proposals, thus stimulating the transfer of additive technologies to the industrial sector of the region.

\section{Acknowledgment}

The study was performed as part of the state order No. $2.9320 .2017 / 8.9$

\section{References}

[1] M. Burns, Automated Fabrication: Improving Productivity in Manufacturing, USA: PTR Prentice Hall, 1993, pp. 123-136.

[2] L. M. Chervyakov, N.A. Bychkova, N.V. Yeliseyeva, A.N. Grechukhin, Transfer of additive manufacturing: industry of Kursk region, Kursk: University book publisher, 2016, pp. 83-97.

[3] V.V. Kuts, Razumov M.S., Grechukhin A.N., Bychkova N.A, "Improving the quality of additive methods for forming the surfaces of odd-shaped parts with the application of parallel kinematics mechanisms", International Journal of Applied Engineering Research, vol. 24, pp. 11832-11835, 2016.

[4] O. Luksha, P. Sushkov, A. Yanovsky, "Center for technology commercialization organizational development: how to create, manage, organize monitoring and evaluation activities", Science and technology commercialization, pp. 37-25, April 2006 [2 $2^{\text {nd }}$ conf. Science and technology commercialization, p. 325, 2006]

[5] A. Kadochnikov, V. Popov, A. Tokarev, O. "Yakubailik, The formation of a GIS Internet portal for monitoring the state of natural environment and resources", Journal of Siberian Federal University. Engineering \& Technologies, vol. 5, pp. 223-337, 2008.

[6] C. A. Ignatiev, V. V. Gorbunov, A. A. Ignat'ev, "Process monitoring as part of the system of quality management", Bulletin of Saratov state technical University, vol. 2, pp. 21-25, 2009.

[7] M. B. Crimson, S. P. Molchanov, S. V. Tret'yakov, L. A. Ermakov, L. D. Pavlova, O. A. Kondratova, "Development of a system of indicators to monitor universities in the field of e-learning and distance educational technologies", Open and distance education, vol. 4, pp. 10-13, 2013.

[8] G. I. Gumerova, E. S. Shaimiev, "The model of management of technological innovations within the technological competitiveness of newly industrialized and industrially developing countries (theoretical aspect)", National interests: priorities and security, vol. 19, pp. 19-29, 2010.

[9] V. L. Dobroskok, L. N. Abduraimov, S. I. Chernyshov "Rational orientation of products in their layer-by-layer shaping on the basis of the original triangulated $3 \mathrm{~d}$ models", Scientific notes of the Crimean engineering and pedagogical University, vol. 24, pp. 13-21, 2010.
[10] S. Byun Hong, H. Lee Kwan, "Determination of optimal build direction in rapid prototyping with variable slicing", Int. J. Adv. Manuf. Technol. Vol. 28, pp. 307-313, 2006.

[11] P. Lan. S. Chou, L. Chent, "Curriere Determining fabrication orientations for rapid prototyping with stereolithography apparatus" Computer - Aided Design, vol. 29, pp. 53-62, 1997.

[12] S. Byun Hong, H. Lee Kwan, "Optimal part orientation of rapid prototyping using a genetic algorithm”, Computers \& Industrial Engineering, vol. 13, pp. 426-431, 2004.

[13] J. Hur, K. Lee, "The development of a CAD environment to determine the preferred build-up direction for layered manufacturing", Int. J. Adv. Manuf. Technol, vol. 14, pp. 247-254, 1998.

[14] J. Y. Kim, K. Lee, J.C. Park. "Determination of optimal part orientation in stereolithographic rapid prototyping", Mechanical Design and Production Engineering, vol. 11, pp. 73-78, 1994.

[15] S. H. Massod, W. Rattanawong, P. Iovenitti, "A generic algorithm for part orientation system for complex parts in rapid prototyping", J. Mater. Process. Technol, vol. 139, pp. 110-116, 2003.

[16] S. H. Masood, W. Rattanawong, "A generic part orientation system based on volumetric error in rapid prototyping", J. Adv. Manuf. Technol, vol. 19, pp.209-216, 2002.

[17] V.A. Grechishnikov, V.B. Romanov, P.M. Pivkin, V.V. Kuts, M.S. Razumov, A.N. Grechukhin, S.Y. Yurasov, "Errors in shaping by a planetary mechanism" Russian Engineering Research, vol 9, pp. 824826, 2017.

[18] S. K. Singhal, A. P. Pandey, P. M. Pandey, A. K. Nagpal, "Optimum part deposition orientation in stereolithography", Computer-Aided Design \& Applications, vol. 2. pp. 319-328, 2005. 